Acta vet. scand. $1967,8,184-185$.

Brief Communication

\title{
MYCOPLASMOSIS: DEMONSTRATION OF PATHOGENICITY OF A DANISH STRAIN OF MYCOPLASMA
}

During the fall of 1966 several strains of Mycoplasma were isolated from semen samples of bulls. A strain " $K$ " isolated from a bull with simultaneous occurrence of leucocytes and mycoplasmas in the semen was selected for a series of experiments; the mammary gland was chosen as pilot organ.

Materials and Methods. Two cows in late lactation were used in three experiments.

Experiment 1. Cow no. 1 was infected (Dec. 23, 1966), by infusion of $2.0 \mathrm{ml}$ 72-hour-old broth culture in the left front quarter. Number of viable cells per ml was $10^{7}$.

Experiment 2. One month later cow no. 1 was infected in the left hind quarter with the same number of viable mycoplasmas as in the first trial.

Experiment 3. Cow no. 2 was infected (Jan. 24, 1967) in the left front quarter with a smaller number of viable cells, namely $10^{5} \times 2$.

Both cows were slaughtered Febr. 22, 1967.

Clinical and laboratory findings. Experiment 1. The milk secretion from the infected quarter dropped from 2.51 to 0.21 within 24 hrs. after infection and remained on that level. The secretion became watery; after $48 \mathrm{hrs}$. flakes of fibrin were seen. After 4 days the secretion resembled cooked cereal from which a watery fluid exuded. This type of secretion persisted for a week, after which it returned to normal. Three days after exposure the leucocyte count was $60 \mathrm{mill} . / \mathrm{ml}$; this level was kept for a week, although with fluctuations from 25 to 60 mill. per $\mathrm{ml} ; 14$ days after infection the count was normal. Mycoplasmas could be isolated only for 12 days; the number of viable organisms was as high as $10^{8}$ per $\mathrm{ml}$.

Experiment 2. The milk secretion, cell count and appearance of the milk remained normal, but mycoplasmas could be isolated intermittently from the infected quarter throughout the period of observation.

Experiment 3. The results were in agreement with those of experiment 1 concerning the inoculated quarter, except that the abnormal milk secretion persisted until slaughtering, and that mycoplasmas could be isolated throughout that period. Unlike in experiment 1 the infection spread to the left hind quarter. 
After slaughtering mycoplasmas were isolated from both of the left quarters, and also from the left mammary lymph node, which was twice as big as the right one.

Histological findings. Cow no. 1. Typical lesions were seen only in the left front quarter. In the teat cistern subepithelial foci of lymphocytes mixed with a few eosinophils were found. The overlying epithelium was hyperplastic. The ventral part of the gland was fibrotic, infiltrated with lymphoid cells, and there was lobular atrophy. The dorsal part had normal alveoli as well as alveoli filled with eosinophilic leucocytes. The ducts contained detritus, often calcified, dilating the lumens and causing atrophy and loss of epithelial cells. Periductal infiltrates of plasma cells and eosinophils were present to a high degree. - The left hind quarter had lesions in the teat cistern consisting of subepithelial foci of lymphocytes. The glandular tissue was fibrotic with scattered lymphoid foci. The right quarters appeared normal.

Cow no. 2. Lesions of a chronic character as described in cow no. 1 were found in the left front and hind quarters, but additional lesions of ductular epithelial hyperplasia with occlusion of ducts were seen. Furthermore, acute lesions with degeneration of alveolar cells, penetration of alveolar walls with eosinophilic leucocytes and macrophages, periacinous infiltration of plasma cells and eosinophils were found, especially in the dorsal part of the left hind quarter, where alveoli in normal secretion were still present.

The right mammary lymph node appeared normal, while the left one showed a pronounced reticulum cell hyperplasia.

It is concluded that the strain " $K$ " is pathogenic and able to produce a typical eosinophilic mastitis, which may or may not spread from one quarter to another. Infection in one quarter seems to leave some immunity in the same-sided quarter. The microscopic picture varies from acute to chronic mastitis. The acute stage is characterized by extensive accumulations of eosinophilic granulocytes in the interstitia and alveoli, the chronic stage by fibrosis, lymphoid and epithelial hyperplasia, and lobular atrophy.

\section{Henning Ern $\varnothing$}

State Veterinary Serum Laboratory, Copenhagen, Denmark.

(Received May 5, 1967). 